\title{
BMD BIO-FUEL FOR DIESEL ENGINES
}

\author{
Lech Sitnik \\ Wroclaw University of Technology \\ Institute of Machine Design and Operation, Mechanical Faculty \\ Eukasiewicza Street 7/9, 50-371 Wroclaw, Poland \\ tel.: +48 71 3477918, fax: +48713477918 \\ e-mail:lech.sitnik@pwr.wroc.pl \\ Artur Malinowski, Anna Matuszewska \\ Automotive Industry Institute \\ Department of Fuels and Renewable Energy \\ Jagiellonska Street 55, 03-301 Warszawa, Poland \\ tel.: +4822 7777241, +4822 7777233, fax: +48227777020 \\ e-mail: a.malinowski@pimot.org.pl,a.matuszewska@pimot.org.pl \\ Jacek Biedrzycki \\ Automotive Industry Institute \\ Department of Environmental Protection and Use of Natural Energy \\ Jagiellonska Street 55, 03-301 Warszawa, Poland \\ tel.: +4822 7777233, fax: +48227777191 \\ e-mail: j.biedrzycki@pimot.org.pl
}

\begin{abstract}
The paper regards the use of bio-blends consisting of vegetable oil and higher alcohol (biobutanol) as a new component of diesel fuels. The use of rapeseed oil as one of the components eliminates the need energy-intensive conversion rapeseed oil to FAME. The use of higher alcohol, such as a butanol obtained directly from biomass is in accordance with requirements of the EU on the promotion of renewable energy resources. Experiments on chassis dynamometer with fuels containing $20 \%$ by volume bio-blend (BM) and $80 \%$ of diesel fuels (D) were performed. Main parameters of engine (power output, torque, specific fuel consumption) and the main exhaust gas components (THC, $C O, N O x$ and $P M$ ) showed very promising results.

The properties of different alcohols and engine fuels, properties of investigated fuels, examples of investigations results on the car test chassis bed by NEDC test load and by fuelling the engine with investigated bmd20 and standard diesel fuel, relatives change of pollutants emission and fuel consumption by fuelling the car engine with BMD20 and Diesel fuel, the differences in emission and fuel consumption during fuelling the car engine with BMD20 and Diesel fuel recorded during the test bed investigation of the car, relatives change of pollutants emission and fuel consumption during engine fuelling with BMD20 and Diesel fuel are presented in the paper.
\end{abstract}

Keywords: road transport, biobutanol, rapeseed oil, bio-fuel, combustion engines, air pollution, environmental protection

\section{Introduction}

People are strongly dependent on crude oil for their transport needs. In order to diminish this dependence, we need to introduce clean, $\mathrm{CO} 2$-efficient, secure and affordable transportation fuels. The current production of liquid bio-fuels in the EU25 is less than $1 \%$ of the market. Recent assessments have concluded that the 2010 target: 18 Mt (Mega Tones) of biofuel consumption in 
the transport sector is unlikely to be achieved.

There are three basic possibilities to accomplish this target:

- the use of alcohols (first of all ethanol) and their mixtures with petrol,

- the use of fatty acids esters (methyl or ethyl esters) of vegetable oils and their mixtures with diesel fuel,

- the use of synthetic hydrocarbons produced from synthesis gas coming from biomass and their mixtures with "classical" hydrocarbons.

Nowadays we have an overproduction of ethanol in EU. At the same time we have an overproduction of petrol, and on the other side on the market is observed increasing sales of diesel oil. However, in the nearest future, despite the increase of engine efficiency, the situation will not changes because of our growing fuel needs.

This paper presents a novel way of using alcohols as fuels for a diesel engine. It was shown the use of heavy alcohols as a solvent for straight vegetable oil (this mixture is called the biomix or $\mathrm{BM})$. Such a mixture, after obtaining the density similar to the density of diesel fuel, is mixed with diesel fuel (D) giving biomixdiesel (BMD). In this paper for BMD preparation was used the nbutanol as an alcohol, rapeseed oil and conventional diesel fuel. Long term, bio-butanol is a direct 'Drop-In' replacement for gasoline and has significant potential as an alternative fuel blend with ethanol (in E-85 as a replacement for gasoline).

The old and new technology of butanol production is known as an ABE process and the second generation process using lignocellulosic waste material, respectively. Butanol, like ethanol, can blend with gasoline very well. Furthermore, butanol could be a future option for blending with diesel. Butanol contains more oxygen content compared with the biodiesel, leading to further reduction of soot. NOx emissions can also be reduced due to its higher heat of evaporation, which results in a lower combustion temperature [6]. The butanol has more advantages than the widely used ethanol and FAME. However, the main disadvantage of butanol is low production. Also there is higher production yield for ethanol fermentation process (up to 30 times) comparing with $\mathrm{ABE}$ process. As was mentioned above, we can distinguish conventional ABE fermentation process based on sugars material (cane or beet) or starch (wheat, corn, or rice) which is easily broken down into sugars. Novel technology TMO process is based on a selected group of thermophilic microorganisms (Thermophiles). The optimal feedstock for bioconversions could be waste biomass (e.g. straw, wood chips and paper pulp effluent) and crops specially grown for their high biomass production rate (kenaf, miscanthus and short rotation woody crops). Such sources of raw materials can be described as "cellulosic biomass" because of their high cellulose and hemicellulose content.

Main alcohols used as a fuels component are: methanol, ethanol and n-butanol. These alcohols have different properties. Some of them are presented in Tab.1. They are compared with conventional engine fuels.

Tab.1. The properties of different alcohols and engine fuels

\begin{tabular}{|l|c|c|c|}
\hline \multicolumn{1}{|c|}{ Fuel } & Energy density & Heat of vaporization & $\begin{array}{c}\text { Kinematic viscosity at } \\
20^{\circ} \mathrm{C}\end{array}$ \\
\hline Diesel & $38.6 \mathrm{MJ} / 1$ & $0,47 \mathrm{MJ} / \mathrm{kg}$ & $>3 \mathrm{cSt}$ \\
\hline Gasoline & $32.0 \mathrm{MJ} / 1$ & $0.36 \mathrm{MJ} / \mathrm{kg}$ & $0.4-0.8 \mathrm{cSt}$ \\
\hline Butanol & $29.2 \mathrm{MJ} / 1$ & $0.43 \mathrm{MJ} / \mathrm{kg}$ & $3.64 \mathrm{cSt}$ \\
\hline Ethanol & $19.6 \mathrm{MJ} / 1$ & $0.92 \mathrm{MJ} / \mathrm{kg}$ & $1.52 \mathrm{cSt}$ \\
\hline Methanol & $16.0 \mathrm{MJ} / 1$ & $1.20 \mathrm{MJ} / \mathrm{kg}$ & $0.64 \mathrm{cSt}$ \\
\hline
\end{tabular}

It is interesting that the butanol has similar energy density as petrol. Butanol is very good solvent of heavy hydrocarbons (such diesel fuels). Mixture of these components is homogeneous (it doesn't separate after several months). In contrast, ethanol is slightly soluble in diesel fuel. It is important that the water is nearly insoluble in butanol (in contrast to ethanol which dissolves water 
in any proportion). We used for preparation BMD, 1-butanol, also known as n-butanol, which has a straight-chain structure with the $-\mathrm{OH}$ at the terminal carbon. Another isomer is 2-butanol, also known as sec-butanol, is also a straight-chain alcohol but with the $\mathrm{OH}$ group at an internal carbon. Iso-butanol is a branched isomer with the $\mathrm{OH}$ group at the terminal carbon and tert-butanol refers to the branched isomer with the $\mathrm{OH}$ group at an internal carbon.

\section{Experimental and Results}

Prepared under laboratory conditions mixtures of n-butanol with diesel fuel were investigated on the chassis dynamometer. Obtained results encouraged the further investigations with other mixtures - one of them is presented in previous paper [5].

There were prepared BMD mixtures. In the first step the rape oil (straight vegetable oil) was mixed with butanol as such proportions to obtain a mixture having a density similar to the density of diesel fuel. This mixture is denoted as a BM (Bio Mix). In the second step this fuel (BM) was mixed with conventional diesel fuel (EN 590) to obtain biomixdiesel (denoted as a BMD). These fluids were mixed in the following proportions:

- biomix (BM) $20 \% \mathrm{v} / \mathrm{v}$,

- diesel fuel (D) $80 \% \mathrm{v} / \mathrm{v}$,

giving fuel called as biomixdiesel (BMD20). In contrast to the mixture of ethanol with rape methyl ester and conventional diesel fuel, this mixture is very homogeneous.

The comparison of new fuel with requirements of the standard diesel fuel is presented in Tab.2.

Tab.2. Properties of investigated fuels

\begin{tabular}{|c|c|c|c|c|}
\hline \multirow[t]{2}{*}{ No. } & \multirow[t]{2}{*}{ Property } & \multirow[t]{2}{*}{ Test method } & \multicolumn{2}{|c|}{$\begin{array}{c}\text { Limits } \\
\text { PN-EN } 590\end{array}$} \\
\hline & & & BMD20 & \\
\hline 1 & Cetane number & PN-EN ISO 5165 & 44.4 & $\min 51.0$ \\
\hline 2 & Cetane index & PN-EN ISO 4264 & 46.8 & $\min 46.0$ \\
\hline 3 & Density at $15^{\circ} \mathrm{C}, \mathrm{kg} / \mathrm{m}^{3}$ & PN-EN ISO 12185 & 837.9 & $820.0-845.0$ \\
\hline 4 & $\begin{array}{l}\text { Polycyclic aromatic hydrocarbons, } \\
\%(\mathrm{~m} / \mathrm{m})\end{array}$ & PN-EN 12916 & 1.9 & $\max 11$ \\
\hline 5 & Sulphur content, $\mathrm{mg} / \mathrm{kg}$ & PN-EN ISO 20846 & 5.7 & $\max 10.0$ \\
\hline 6 & Flash point, ${ }^{\circ} \mathrm{C}$ & PN-EN ISO 2719 & $<40.0$ & above 55 \\
\hline 7 & $\begin{array}{l}\text { Carbon residue (on } 10 \% \text { distillation } \\
\text { residue), } \%(\mathrm{~m} / \mathrm{m})\end{array}$ & PN-EN ISO 10370 & 0.48 & $\max 0.30$ \\
\hline 8 & Ash content, $\%(\mathrm{~m} / \mathrm{m})$ & PN-EN ISO 6245 & $<0.001$ & $\max 0.01$ \\
\hline 9 & Water content, $\mathrm{mg} / \mathrm{kg}$ & PN-EN ISO 12937 & 110 & $\max 200$ \\
\hline 10 & Total contamination, $\mathrm{mg} / \mathrm{kg}$ & PN-EN 12662 & $<6.0$ & $\max 24$ \\
\hline 11 & Copper strip corrosion $\left(3 \mathrm{~h}\right.$ at $\left.50^{\circ} \mathrm{C}\right)$ & PN-EN ISO 2160 & class 1 & class 1 \\
\hline 12 & $\begin{array}{l}\text { Lubricity, corrected wear scar } \\
\text { diameter (wsd } 1,4) \text { at } 60^{\circ} \mathrm{C}, \mu \mathrm{m}\end{array}$ & $\begin{array}{l}\text { PN-EN ISO } \\
12156-1 \\
\end{array}$ & 281 & $\max 460$ \\
\hline 13 & Viscosity at $40^{\circ} \mathrm{C}, \mathrm{mm}^{2} / \mathrm{s}$ & PN-EN ISO 3104 & 2.710 & $2.00-4.50$ \\
\hline 14 & $\begin{array}{l}\text { Distillation } \\
\%(\mathrm{~V} / \mathrm{V}) \text { recovered at } 250^{\circ} \mathrm{C} \text {, } \\
\%(\mathrm{~V} / \mathrm{V}) \text { recovered at } 350^{\circ} \mathrm{C} \text {, } \\
95 \%(\mathrm{~V} / \mathrm{V}) \text { recovered at },{ }^{\circ} \mathrm{C} \\
\text { Finish boiling point, }{ }^{\circ} \mathrm{C}\end{array}$ & PN-EN ISO 3405 & $\begin{array}{c}47.3 \\
-- \\
-- \\
349.9 \\
\end{array}$ & $\begin{array}{c}<65 \\
\min 85 \\
\max 360 \\
--\end{array}$ \\
\hline 15 & $\begin{array}{l}\text { Fatty acid methyl ester content, } \\
\text { FAME , } \%(\mathrm{~V} / \mathrm{V})\end{array}$ & PN-EN 14078 & $<1.6$ & $\max 7.0$ \\
\hline 16 & Oxidation stability, g/m3 & PN-ISO 12205 & 66 & $\max 25$ \\
\hline
\end{tabular}

Comparing the results of bio-fuels B20 with quality requirements for diesel fuel it worth to 
note that most of the parameters meet these requirements; however, several parameters deviate from the normative requirements. Cetane number is lower than the required standard that is at least 51 units. This is due to the participation of $20 \%$ biocomponents. Rapeseed oil has a cetane number of the order of 40-50 units [4] and a small addition to the diesel fuel should not drastically reduce the Cetane number. However alcohol is usually characterized by a very high octane number, which is beneficial in case of composing gasoline, added to the diesel fuel can degrade the diesel engine start-up parameters. The process of starting engine and his operation is also influenced by fractional composition of fuel, particularly temperature distillation of $50 \%$ by volume of fuel, T50. The lower the temperature T50 is the easier start, but at too low temperature ignition characteristics fuel property is worsen - Cetane number decreases. The investigations of fuel properties under operating conditions were carried out with a modern diesel engine on the chassis bed dynamometer in the NEDC test. Main output parameters of car engine (power output, torque, specific fuel consumption) and the main exhaust gas component (in this case THC, $\mathrm{CO}, \mathrm{CO}_{2}, \mathrm{NO}_{\mathrm{x}}$, $\mathrm{THC}+\mathrm{NO}_{\mathrm{x}}, \mathrm{PM}$ ) and fuel consumption is evaluated and explain here in $\mathrm{g} / \mathrm{km}$. In Tab. 3. there are presented examples of obtained results.

Tab. 3. Examples of investigations results on the car test chassis bed by NEDC test load and by fuelling the engine with investigated BMD20 and standard Diesel fuel

\begin{tabular}{|c|c|c|c|c|c|c|c|c|}
\hline \multirow{2}{*}{ Emission } & \multirow{2}{*}{ Fuel } & \multicolumn{6}{|c|}{$\begin{array}{c}\text { Pollutants } \\
\mathrm{g} / \mathrm{km}\end{array}$} & $\begin{array}{c}\text { Fuel } \\
\text { consumption, } \\
\mathrm{g} / \mathrm{km}\end{array}$ \\
\cline { 3 - 10 } & & THC & CO & CO2 & NOX & THC+NOX & PM & 6.2467 \\
\hline UDC & BMD20 & 0.1000 & 1.3900 & 163.6367 & 0.1933 & 0.2967 & 0.0042 & 6.1933 \\
\hline UDC & Diesel & 0.0833 & 1.3400 & 162.1367 & 0.2000 & 0.2867 & 0.0053 & 0.467 \\
\hline EUDC & BMD20 & 0.0100 & 0.0367 & 118.7567 & 0.2133 & 0.2267 & 0.0064 & 4.4667 \\
\hline EUDC & Diesel & 0.0100 & 0.0467 & 114.5500 & 0.1600 & 0.1700 & 0.0078 & 4.3167 \\
\hline NEDC & BMD20 & 0.0467 & 0.5367 & 135.2933 & 0.2067 & 0.2533 & 0.0056 & 5.1233 \\
\hline NEDC & Diesel & 0.0367 & 0.5233 & 132.1100 & 0.1767 & 0.2167 & 0.0069 & 5.0100 \\
\hline
\end{tabular}

The fuelling of the car engine with different fuel leads to a diversity of output parameters of the engine. But the differences are not so significant. Differences between the results obtained for the tested BMD20 fuel and diesel fuel are presented below. To better show the results of investigations of pollutant emission, they are presented here as relative to the results obtained by fuelling the engine with the conventional diesel fuel. The results expressed in $\mathrm{g} / \mathrm{km}$ are shown in Tab. 4.

Tab.4. Relatives change of pollutants emission and fuel consumption by fuelling the car engine with BMD20 and Diesel fuel

\begin{tabular}{|c|c|c|c|c|c|c|c|}
\hline \multirow{3}{*}{ Test } & \multicolumn{6}{|c|}{ Pollutants } & \multirow{2}{*}{$\begin{array}{c}\text { Fuel } \\
\text { consumption }\end{array}$} \\
\hline & THC & $\mathrm{CO}$ & $\mathrm{CO} 2$ & $\mathrm{NO}_{\mathrm{x}}$ & $\mathrm{THC}+\mathrm{NO}_{\mathrm{x}}$ & PM & \\
\hline & \multicolumn{7}{|c|}{$\mathrm{g} / \mathrm{km}$} \\
\hline UDC & 0.0167 & 0.0500 & 1.5000 & -0.0067 & 0.0100 & -0.0011 & 0.0533 \\
\hline EUDC & 0.0000 & -0.0100 & 4.2067 & 0.0533 & 0.0567 & -0.0014 & 0.1500 \\
\hline NEDC & 0.0100 & 0.0133 & 3.1833 & 0.0300 & 0.0367 & -0.0013 & 0.1133 \\
\hline
\end{tabular}

The results are presented in graphical form on the Fig. 1. 


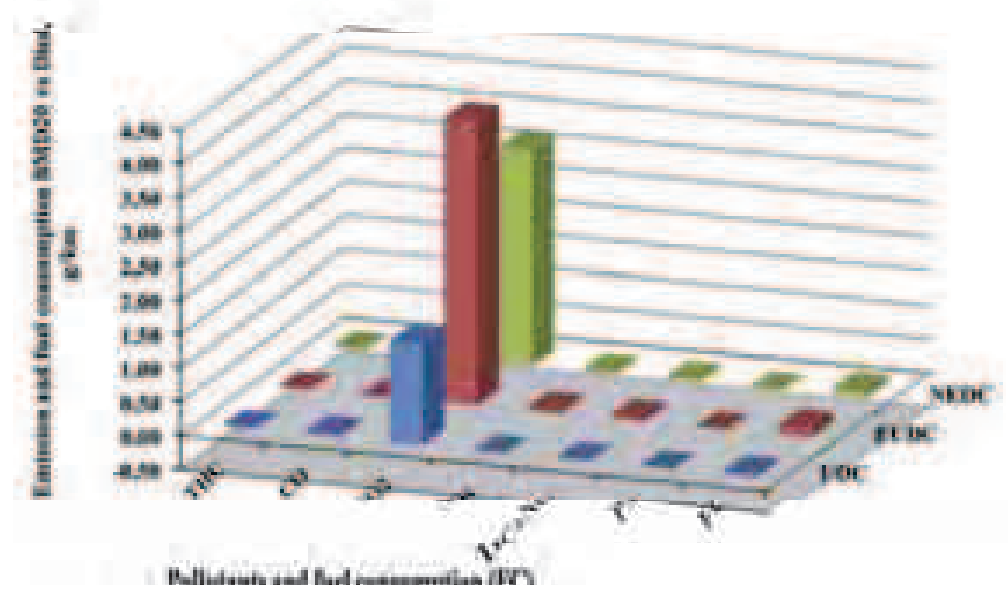

Fig. 1. The differences in emission and fuel consumption during fuelling the car engine with BMD20 and Diesel fuel recorded during the test bed investigation of the car

Research results are interesting. In all phases of the test, during fuelling the engine with BMD20, increasing the carbon dioxide $\left(\mathrm{CO}_{2}\right)$ is observed. Emissions of other toxic components and fuel consumption are not differing from those when the engine is fuelled by conventional fuel.

Small differences in the results are becoming clear when relative changes are expressed in $\%$. The results of this analysis are presented in Tab. 5. and illustrated on Fig. 2.

Tab. 5. Relatives change of pollutants emission and fuel consumption during engine fuelling with BMD20 and Diesel fuel

\begin{tabular}{|c|c|c|c|c|c|c|c|}
\hline \multirow{3}{*}{ Test } & \multicolumn{6}{|c|}{ Pollutants } & \multirow{2}{*}{$\begin{array}{c}\text { Fuel } \\
\text { consumption }\end{array}$} \\
\hline & THC & $\mathrm{CO}$ & $\mathrm{CO}_{2}$ & $\mathrm{NO}_{\mathrm{x}}$ & $\mathrm{THC}+\mathrm{NO}_{\mathrm{x}}$ & $\mathrm{PM}$ & \\
\hline & \multicolumn{7}{|c|}{$\%$} \\
\hline UDC & 20.00 & 3.73 & 0.93 & -3.33 & 3.49 & -20.75 & 0.86 \\
\hline EUDC & 0.00 & -21.43 & 3.67 & 33.33 & 33.33 & -18.38 & 3.47 \\
\hline NEDC & 27.27 & 2.55 & 2.41 & 16.98 & 16.92 & -18.93 & 2.26 \\
\hline
\end{tabular}

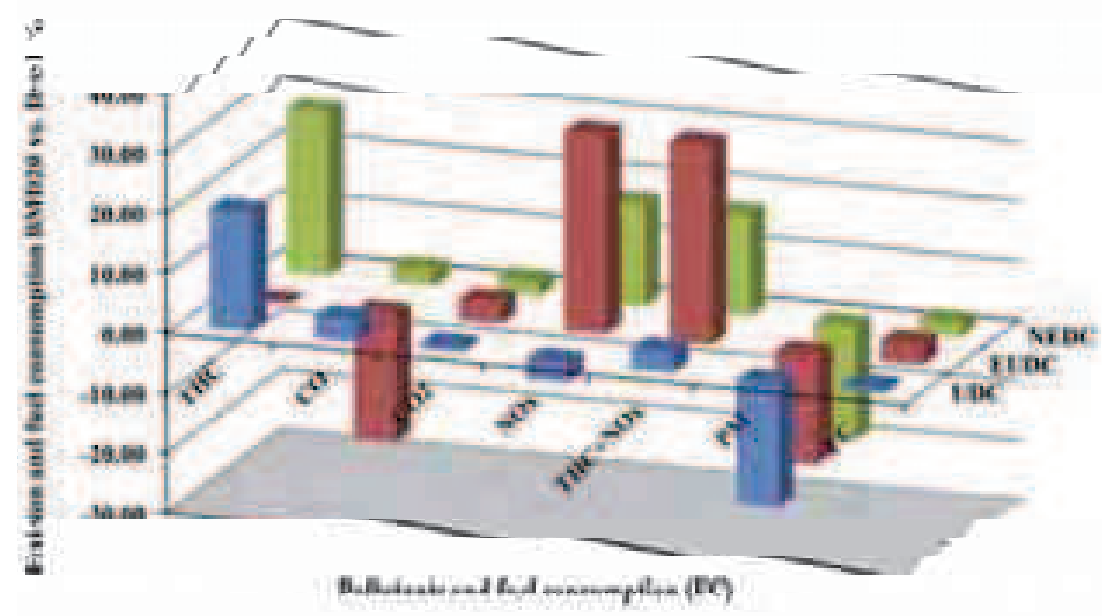

Fig. 2. Relative change of emissions and fuel consumption of the car engine fuelled with BMD20 and diesel oil

During fuelling the car engine with the BMD20, the fuel consumption is not significantly different (less that 3.5\%) from observed for Diesel oil. The differences in the emission of 
pollutants are depended on the test phase (UDC or EUDC). For example the emission of THC in the EUDC phase is the same as that recorded for diesel oil, but the quantity THC grows in UDC phase. Thus in full test (NEDC) the relative emission of THC grows. Other trend is observed for carbon monoxide (CO) emissions. In the UDC phase emission of CO slightly increases, in the EUDC phase significantly decreases (more then 21\%) so, therefore in the NEDC test the emission of CO slightly grows.

The emissions of NOx grows, first of all, in the EUDC phase. This is understandable if we take in into consideration the engine load - the higher combustion temperatures (peaks) in this phase favour the formation of nitrogen oxides. In the same phase, the emission of THC neither increases nor decreases, so in the entire test, the summary quantity of $\mathrm{THC}+\mathrm{NO}_{\mathrm{x}}$ increases (the emission of THC increases in the UDC phase).

It is important that, the PM emission decreases in all phases of test. The decrease is significant, about $21 \%$ in the UDC phase and more than $18 \%$ in the EUDC phase.

The above results were obtained without any change of engine control parameters (the engine control parameters were the same as during supplying the engine with conventional diesel fuel). It appears that after optimization of engine control parameters the results will be much better.

\section{Conclusions}

There have been given the first investigations results of application of heavy alcohols as a component of diesel fuel. There have been presented results for mixture of butanol (as heavy alcohol), rape oil (as vegetable oil) and conventional diesel fuel. This mixture was called the biomixdiesel (BMD). The tests showed very promising results.

It is important is that for practically the same fuel consumption, the emissions of main toxic compounds decreased. Particularly important is the decrease of emissions for particle matter (PM). Increase of emissions of NOx is avoiding today's in modern engines equipped with the SCR catalyst, so the emissions of nitric oxides can be minimized.

The production of butanol is known. There is observed trend in transformation of ethanol plants into butanol one. There has also been presented another way to use alcohols (and vegetable oils - without transesterification process) as diesel engine fuel.

It can be concluded, that the expanding production o butanol and European production of vegetable oils will contribute to fulfil expected requirements of European Union connected with biofuels.

The future works will focus on better adjusting of the engine to new fuel (especially engine control parameters), as well as blending a new fuels for specific exploitation needs.

\section{References}

[1] European Commission. Directorate-General for Research Sustainable Energy Systems, Biofuels in the European Union. A vision for 2030 and beyond. Final report of the Bio-fuels Research Advisory Council, ISBN 92-79-01748-9, 2006.

[2] Appendix, C., Bio-fuels and bio-based chemicals (background), http://www.dni.gov/nic/ PDF_GIF_confreports/disruptivetech/appendix_C.pdf.

[3] Sitnik , L. J., New ecofuel for diesel engines, Journal of POLISH CIMAC, Science publication of Editorial Advisory Board of Polish CIMAC, pp. 155-159, Gdansk 2009.

[4] Rakopoulos, D., Rakopoulos, C., Giakoumis, E., Dimartos, A., Kyritsis, D., Effects of butanol-diesel fuel blends on the performance and emissions of a high-speed DI diesel engine, Energy Convers Manage, 51, 1989-97, 2010.

[5] Czarnocka, J, Malinowski, A, Sitnik, L., Assessment of physicochemical properties ternary bio-fuels to power diesel engines, Archiwum Motoryzacji, 4, pp. 37-42, 2011. 